\title{
Impact of lumbopelvic pain on postural balance during sit-to-stand activity in pregnant women: a cross-sectional study
}

\author{
Impacto da dor lombopélvica no equilíbrio \\ postural durante a atividade do sentar-levantar \\ em mulheres grávidas: estudo transversal
}

Impacto del dolor lombopélvica em el equilibrio
postural durante la actividad del sentar-levantar em
mujeres embarazadas: estudio transversal

Silvia Oliveira Ribeiro Lira ${ }^{[a]}$, Vanessa Patrícia Soares de Sousa®[a], Caroline Nayane Alves Medeiros ${ }^{[b]}$, Elizabel de Souza Ramalho Viana $[b]^{*}$

[a] Universidade Federal do Rio Grande do Norte (UFRN), Santa Cruz, RN, Brazil

[b] Universidade Federal do Rio Grande do Norte (UFRN), Natal, RN, Brazil

Abstract

Introduction: The emergence of painful pathologies during gestation, such as lumbopelvic pain (LPP), can influence in the achievement of functional activities, such as sit-to-stand, throughout the gestational period. Objective: To compare the variables of static and dynamic postural balance (sit-to-stand activity) among pregnant women with and whitout lumbopelvic pain and the outcome variables between the gestational trimesters. Method: A total of 100 pregnant women participated in this study allocated as follows: 51 in

\footnotetext{
* SORL: MS, e-mail: oliveira.silviaribeiro@gmail.com VPSS: PhD, e-mail: vanessapfisio@gmail.com CNAM: Undergrad, e-mail: carolinenayane@hotmail.com ESRV: PhD, e-mail: elizabelviana@gmail.com
} 
the LPP group and 49 in the group without LPP. All participants were subjected to an evaluation protocol: filling an identification form, Analogic Visual Scale (AVS) and Oswestry Disability Index (ODI). Evaluation of postural balance was subsequently performed using the Balance Master System ${ }^{\circledR}$. Results: $64.7 \%$ of women during the third trimester of pregnancy reported LPP. No statistically significant differences were found between LBP presence or absence in postural balance variables $(p>0.05)$. However, gestational age influenced the VFEC variable $(\mathrm{p}=0.001)$. Conclusion: Women during the third gestational trimester presented complaints of lumbopelvic pain. However, the data acquired suggest that women with LPP do not have alterations in postural balance during sit-to-stand movement when compared to pregnant women without pain.

Keywords: Pain. Pain Measurement. Pregnancy. Physical Therapy Specialty.

\section{Resumo}

Introdução: $O$ surgimento de patologias dolorosas na gestação, como a dor lombopélvica (DLP), podem influenciar na realização de atividades funcionais, como o sentar-levantar, ao longo do período gestacional. objetivo: Comparar as variáveis do equilíbrio postural estático e dinâmico (atividade do sentar-levantar) entre gestantes com e sem dor lombopélvica e as variáveis-desfecho entre os trimestres gestacionais. Método: Participaram desse estudo 100 mulheres grávidas alocadas da seguinte maneira: 51 gestantes no grupo com DLP e 49 gestantes no grupo sem DLP. Todas as participantes foram submetidas ao protocolo de avaliação: preenchimento de ficha de identificação, Escala Visual Analógica (EVA) e Oswestry Disability Índex (OII), seguido da avaliação do equilíbrio postural por meio do Balance Master System ${ }^{\circledR}$. Resultados: $64,7 \%$ das mulheres no terceiro trimestre gestacional relataram DLP. Não foram encontradas diferenças estatisticamente significativas entre a presença/ausência da DLP nas variáveis do equilíbrio postural ( $p>0,05)$. Contudo, observou-se diferença estatística ao analisar a idade gestacional na variável velocidade de oscilação em superfície firme de olhos fechados (VFOF) ( $p=0,001)$. Conclusão: Mulheres no terceiro trimestre gestacional apresentam queixas de dor lombopélvica. Entretanto, os dados obtidos sugerem que mulheres com DLP não tem alteração no equilíbrio postural durante o movimento sentar-levantar quando comparadas a gestantes sem dor.

Palavras-chave: Dor. Medição da Dor. Gestação. Fisioterapia.

\section{Resumen}

Introducción: El surgimento de patologias dolorosas em la gestación, como el dolor lombopélvico (DLP), puede influir em la realización de atividades funcionales, como el sentarse, durante el embarazo. Objetivo: Comparar las variables delequilibrio postural estático y dinâmico (actividad del sentar-levantar) entre gestantes com y sin dolor lombopélvico y las varibles desenlace entre los trimestres gestacionales. Método: Participaron de esse estúdio 100 mujeres embarazadas assignadas de la siguiente manera: 51 gestantes en el grupo com DLP y 49 gestantes en el grupo sin DLP. Todas las participantes fueron sometidas al protocolo de evaluación: llenado de ficha de identificación, Escala Visual Analógica (EVA) y Oswestry Disability Índex (OII),seguido de la evaluación del equilíbrio postural através del Balance Master System ${ }^{\circledR}$. Resultados: 64,7\% de las mujeres en el tercer trimestre gestacional informaron DLP. No se encontraron diferencias estadísticamente significativas entre la presencia/ ausência de la DLP em las variables del equilíbrio postural $(p>0,05)$. Sin embargo, se observo diferencia estadística al analizar la edad gestacional em la variable velocidade de oscilación en superfície firme de ojos cerrados (VFOC) ( $p=0,001)$. Conclusión: Las mujeres en el tercer trimestre gestacional presentan quejas de dolor lombopélvico. Sin embargo, los datos obtenidos sugieren que las mujeres com DLP no tienen alteración em el equilíbrio postural durante el movimento sentarse cuando se comparan a las gestantes sin dolor.

Palabras clave: Dolor. Medición del Dolor. Embarazo. Fisioterapia. 


\section{Introduction}

The several hormonal, physiological and anatomical changes that occur during pregnancy can result in changes to the mother's body [1]. Among these changes we can include: weight gain, changes in the center of gravity (CG) [2], increased joint laxity [1], decreased control and neuromuscular coordination [1,3] and postural oscillation [4]. These modifications are capable of altering postural balance [5] and can result in the development of painful symptomatology [6], especially in the lumbar region [7], leading to influence the performance of functional activities [8] such as sit-to-stand [9].

The performance of going from a sitting to a standing position varies according to adaptation to task requirements, to the individual and the environment. Operationally, the sit-to-stand movement is defined as a successful transfer of the body's center of mass (CM) from a sitting to a stable standing position. This requires good coordination between the central nervous system (CNS) and the neuromuscular system $[9,10]$. During pregnancy, postural instability, lumbopelvic pain (LPP) and fatigability may be limiting factors for the execution of this movement.

In order to perform these functional activities without risk of falling, it is necessary to maintain postural balance, defined as the ability to maintain the CM within the limits of the support base [11]. This balance is attributed to the postural control system, which refers to CNS-mediated functions of the sensory, visual and vestibular systems [12].

During pregnancy, LPP is one of the most common, serious and disabling complaints $[13,14]$. Its prevalence is greater than $50 \%$ in pregnant women [7, $15]$, and it can have great impact on the quality of life of pregnant women $[15,16]$. Currently, it is suggested that the LPP pathophysiology involves a complex interrelationship between the proprioceptive neuromuscular and bone unit, based on the concept of lumbopelvic stabilization.

\section{Objectives}

Given that pregnancy represents a period of intense physical and emotional adjustments for the woman, it is essential to understand and follow-up the musculoskeletal changes and the resulting compensatory postural adjustments, as well as complaints of discomfort common to the pregnancy-puerperal cycle. In addition, LPP may exert an influence on the pregnant woman's daily activities, similar to what occurs in other populations. However, studies that seek to elucidate questions regarding analysis of postural balance and the impact of lumbopelvic pain during pregnancy are scarce. Thus, the objective of this study was to compare the variables of static and dynamic postural balance (sitto-stand activity) among pregnant women with and without lumbopelvic pain and the outcome variables between the gestational trimesters.

\section{Methods}

Design, setting and participants

This is an analytical cross-sectional study in accordance with the recommendations defined in Stregthening the Reporting of Observational Studies in Epidemiology (STROBE). This study was developed at the Laboratory for Neuromuscular Performance Analysis (LAPERN) of the Department of Physical Therapy from the Federal University of Rio Grande do Norte - UFRN. The study was submitted to the Research Ethics Committee for Human Beings of UFRN and approved under protocol number 719.939. All volunteers signed the Clear and Informed Consent Form (ICF), in accordance with the provisions of Resolution 466/12 of the National Health Council.

The sample size was obtained through the openepi.com site. A power of $80 \%, 95 \%$ confidence interval and the following means were considered: group with pain $=2.64+/-0.4$ and group with no pain $=2.87+/-0.3$. These data were obtained from a previous pilot study with 20 pregnant women: 10 with pain and 10 with no pain. Therefore, the suggested sample number was 76 volunteers (38 per group).

The study population consisted of women during the second and third gestational trimesters (between 14 and 37 weeks), residing in the city of Natal-RN participating in the Preparatory Course for Gestation, Childbirth and Postpartum (CPGPP) promoted by the Physiotherapy Department of the UFRN. A total of 150 women were selected during the study period (April 2014 to June 2016), enrolled by a non-probabilistic sampling process by convenience. The presence/absence of LPP was considered a grouping factor. Thus, the pregnant women were allocated into 2 study groups: Group 
with LPP (LPPG) and Group without LPP (WLPP). The sample of this study consisted of 100 women selected according to the eligibility criteria and allocated as follows: 52 pregnant women into the LPPG and 48 pregnant women into the group WLPP (Figure 1).
The gestational trimester was also considered a grouping factor. Thus, the pregnant women were allocated into the following groups: Group $2^{\text {nd }}$ Trimester with LPP (2LPPG), Group $3^{\text {rd }}$ Trimester with LPP (3LPPG), Group $2^{\text {nd }}$ Trimester without LPP (2WLPP) and Group $3^{\text {rd }}$ Trimester without LPP (3WLPP).

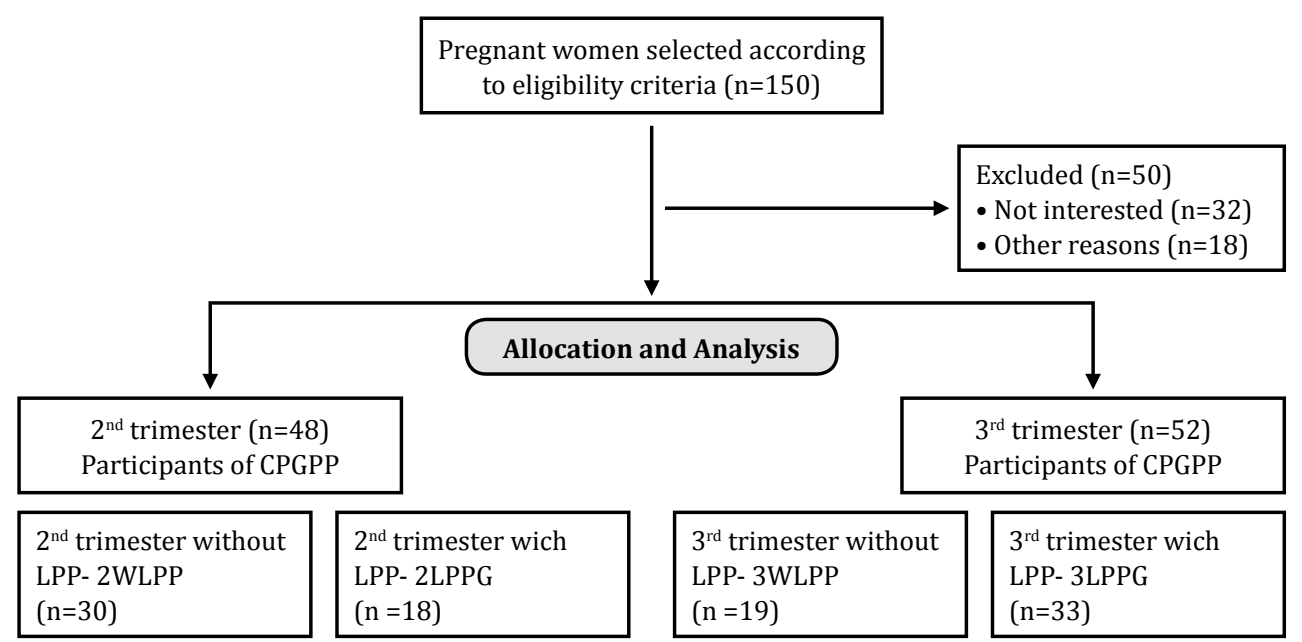

Figure 1-Study distribution flowchart.

The following inclusion criteria were adopted: (1) not presenting clinical and obstetric changes (lowrisk pregnant women); (2) aged between 18 and 37 years; (3) during the second ( $14^{\text {th }}$ to $21^{\text {st }}$ weeks) or third $\left(27^{\text {th }}\right.$ to $32^{\text {nd }}$ weeks $)$ gestational trimesters; confirmed by ultrasonography; (4) nulliparous women; (5) single fetus pregnancy; (6) not using medication/substances that affect their balance; (7) no history of altered balance before pregnancy; (8) no previous surgeries in the spine, pelvis, hip and knee; and (9) absence of musculoskeletal, cardiorespiratory and neurological disorders that would hinder the performance of the evaluation protocols and treatment.

Pregnant women who: 1) failed to perform any of the evaluation steps; or 2) withdrew consent to participate were excluded from the study.

\section{Evaluation Protocol: variables and measurement}

All participants were subjected to the following evaluation protocol:

1) Evaluation form containing sociodemographic, clinical, anthropometric and obstetric information of the sample;
2) Evaluation of lumbopelvic pain using the Visual Analogue Scale (VAS) and the Oswestry Disability Index (ODI).

VAS is an instrument graded from 0 (zero) to 10 (ten), where 0 represents an absence of pain, and 10 is the maximum tolerable pain. The pain intensity is divided into categories, in which: 1 to 2 is considered of mild intensity; 3 to 7 is moderate; 8 to 9 is intense; and 10 is unbearable. This instrument has been used for evaluating pain intensity in populations of pregnant women $[16,17]$.

The Oswestry Disability Index (ODI) was validated for the Brazilian population by Vigatto et al. [18], and was used in this study to assess the level of disability generated by pain. It contains 10 domains: pain intensity, personal care, lifting, ability to walk, sit and stand, sleep quality, sex life, social life and ability to travel. Each domain contains six statements that are scored from 0 (minimum degree of difficulty during the activity) to 5 (maximum degree of difficulty). The final score is expressed as a percentage: $0 \%-20 \%$ indicates minimum disability, $21-40 \%$ moderate disability, 41\%-60\% severe disability, 61\%-80\% 
is crippling disability, and $81 \%-100 \%$ represents complete disability [19].

3) Assessment of postural balance by the Balance Master System ${ }^{\circledR}$, in which 2 tests were selected: Modified Clinical Test of Sensory Interaction on Balance (mCTSIB) and Sit-to-stand (STS).

The mCTSIB provides an objective analysis of postural balance control, since it quantifies the velocity of postural oscillation during four sensorial conditions: eyes open on a firm surface, eyes closed on a firm surface, eyes open on an unstable surface and eyes closed on an unstable surface [20].

To carry out the tests, the pregnant women were initially placed on a platform on a firm surface and were instructed to remain with their arms at their sides, fixing their gaze on a specific point on the horizon. Next, they were asked to remain with their eyes closed still in the same position. The sequence was repeated with the pregnant woman positioned on an unstable surface, and each attempt lasted 10 seconds (time established by the device).

On the other hand, the STS test evaluates dynamic balance when standing up through weight transfer, CG displacement velocity, weight symmetry and displacement rate (\% of weight). The pregnant women were instructed to sit on two wooden blocks with their upper limbs at their sides and hips and knees flexed at $90^{\circ}$. Next, they were asked to safely get up from the chair without support and as fast as possible. The transfer from sitting to standing occurred immediately after the appearance of the word "Go" on the computer screen and the volunteer remained in the final position for 30 seconds. Three repetitions of this movement were performed with a 30 second interval between each of them.

Statistical analysis

Statistical analysis was performed using the SPSS program (version 20.0). A descriptive analysis was carried out through measures of central tendency, dispersion, absolute and relative values to characterize the sample regarding sociodemographic, obstetric and anthropometric data. The Shapiro-Wilk test was subsequently applied to verify the normality of the data. The results are presented as mean and standard deviation.
Inferential statistical analysis was performed with the purpose of detecting the possible influence of LPP on postural balance variables, and then the influence of gestational age on postural balance variables. The Mann Whitney test was used to compare postural balance variables, considering the presence or absence of lumbopelvic pain and according to the gestational trimesters. A significance level of $p<5 \%$ and a $95 \%$ confidence interval (CI) were adopted.

The G* Power software program (Germany, 19922014, version 3.1.9.2) was used considering an effect size of 0.5 , power of 0.8 , level of significance of 0.05 and non-directional type of distribution. The power of the study was $80 \%$.

\section{Results}

Sociodemographic, obstetric and anthropometric variables for characterization of the sample are shown in Table 1.

Table 1 - Sociodemographic, obstetrical and anthropometric chatacteristics of pregnant women participating in the study

\begin{tabular}{|c|c|c|}
\hline Variables & $\begin{array}{c}2^{\circ} \text { Trimester } \\
(n=48)\end{array}$ & $\begin{array}{c}3^{\circ} \text { Trimester } \\
(\mathrm{n}=52)\end{array}$ \\
\hline \multicolumn{3}{|l|}{ Sociodemographic data } \\
\hline Age (in years) & $29.75 \pm 4.87$ & $29.74 \pm 3.68$ \\
\hline Education (in years) & $16.76 \pm 3.03$ & $17.13 \pm 2.78$ \\
\hline \multicolumn{3}{|l|}{ Marital status } \\
\hline Married & $75.5 \%(37)$ & $80.4 \%(41)$ \\
\hline Has a companion & $18.4 \%(9)$ & $17.6 \%(9)$ \\
\hline Does not have a companion & $6.1 \%(3)$ & $2 \%(1)$ \\
\hline \multicolumn{3}{|l|}{ Income (minimum wage) } \\
\hline 1 to 2 & $6.1 \%(3)$ & - \\
\hline 3 to 4 & $20.4 \%(10)$ & $27.5 \%(14)$ \\
\hline$>4$ & $61.2 \%(30)$ & $62.7 \%(32)$ \\
\hline Did not answer & $12.2 \%(6)$ & $9.8 \%(5)$ \\
\hline \multicolumn{3}{|l|}{ Obstetric data } \\
\hline GA (in weeks) average & $\begin{array}{c}20.00 \\
(17.00-21.00) \\
\end{array}$ & $\begin{array}{c}29.00 \\
(27.00-31.00) \\
\end{array}$ \\
\hline \multicolumn{3}{|l|}{ Anthropometric data } \\
\hline Weight (in Kg) & $67.27 \pm 10.30$ & $68.33 \pm 9.55$ \\
\hline Height (in Meters) & $1.63 \pm 5.51$ & $1.62 \pm 5.68$ \\
\hline \multicolumn{3}{|l|}{ Pain } \\
\hline VAS & $0(0.0-5.0)$ & $3.0(0.0-5.0)$ \\
\hline
\end{tabular}

Note: The values for the quantitative variables are presented as mean (standard deviation) or median (minimum-maximum). Categorical variables are displayed through relative frequencies. VAS: Visual Analogue Scale. 
The frequency of LPP in this study was $36.7 \%$ ( $n=18$ ) during the second trimester and $64.7 \%$ $(\mathrm{n}=33)$ during the third trimester. The volunteers who presented LPP complaints were evaluated for the disability level generated by pain according to the ODI. Of the 51 participants with pain, $68.6 \%(\mathrm{n}=35)$ reported minimal disability, $29.4 \%(\mathrm{n}=15)$ reported moderate disability and only $2 \%(n=1)$ reported severe disability.

Considering the presence/absence of LPP, no statistically significant differences were found for postural balance variables when comparing pregnant women with and without LPP $(p>0.07)$. In analyzing the influence of gestational age on postural balance variables considering the presence/absence of LPP, a statistically significant difference was observed only for the VFEC variable (Velocity of oscillation on a Firm surface and Eyes Closed) on the (mCTSIB) test for pregnant women during the $3^{\text {rd }}$ trimester $(p=0.001)$ ( Table 2).

A trend towards statistical significance was observed for the variables VFEO (Velocity of oscillation on a Firm surface and Eyes Open) $(p=0.05)$ for pregnant women during the $3^{\text {rd }}$ trimester and SRL (weight Symmetry between Right and Left lower limbs) ( $p=0.05$ ) for pregnant women during the $2^{\text {nd }}$ trimester (Table 2 ).

Table 2 - Evaluation of postural balance variables (static and dynamic) considering the gestational trimesters depending on the presence or absence of lumbopelvic pain, presented by median and interquartile range

\begin{tabular}{|c|c|c|c|c|c|c|c|}
\hline & \multicolumn{2}{|c|}{$2^{\text {nd }}$ trimester } & \multirow[b]{2}{*}{$\mathbf{p}$} & \multicolumn{2}{|c|}{$3^{\text {rd }}$ trimester } & \multicolumn{2}{|c|}{ Analysis } \\
\hline & With DLP & No DLP & & With DLP & No DLP & $\mathrm{H}$ & $p$ \\
\hline \multicolumn{8}{|l|}{ MCTSB } \\
\hline VFEO(in \%s) & $0.30(0.20-0.30)$ & $0.30(0.20-0.30)$ & 0.64 & $0.20(0.20-0.30)$ & $0.30(0.20-0.32)$ & 4.175 & 0.05 \\
\hline VFEC(in \%s) & $0.30(0.20-0.42)$ & $0.30(0.20-0.40)$ & 0.61 & $0.20(0.20-0.30)$ & $0.40(0.30-0.40)$ & 10.600 & $0.001^{€}$ \\
\hline VUEO(in \%s) & $0.45(0.27-0.60)$ & $0.50(0.30-0.60)$ & 0.54 & $0.50(0.30-0.70)$ & $0.50(0.40-0.62)$ & 2.056 & 0.76 \\
\hline VUEC(in \%s) & $0.60(0.40-0.95)$ & $0.80(0.40-1.30)$ & 0.28 & $0.90(0.40-1.50)$ & $0.90(0.57-1.92)$ & 3.884 & 0.80 \\
\hline \multicolumn{8}{|l|}{ STS } \\
\hline TT (in s) & $0.56(0.38-0.86)$ & $0.55(0.37-0.73)$ & 0.57 & $0.50(0.35-0.69)$ & $0.62(0.32-0.75)$ & 0.981 & 0.60 \\
\hline SR (in \%) & $12.33(9.75-14.25)$ & $13.00(11.00-15.00)$ & 0.21 & $12.00(10.00-16.00)$ & $11.00(10.00-13.25)$ & 1.372 & 0.50 \\
\hline$S($ in $\%$ s) & 2.45 (1.95-3.32) & $2.90(1.90-4.00)$ & 0.31 & $2.90(2.28-3.70)$ & $3.00(2.15-3.45)$ & 2.025 & 0.53 \\
\hline WSLR (in\%) & $9.00(5.5-12.25)$ & $4.00(2.00-10.00)$ & 0.05 & $6.00(3.00-10.00)$ & $9.00(3.5-11.25)$ & 4.436 & 0.45 \\
\hline
\end{tabular}

Note: ${ }^{€}$ statistically significant diferences $(p<0.05)$ - test of Mann-Whitney. MCTSIB: Modified Clinical Test of Sensory Interaction on Balance; VFEO: Oscillation speed (deg/sec) on a stable surface with eyes open; VFEC: Oscillation speed (deg/sec) on a stable surface with eyes closed; VUEO: Oscillation speed (deg/sec) on an unstable surface with eyes open; VUEC: Oscillation speed (deg/sec) on an unstable surface with eyes closed; STS: Sit-to-stand; TT: Transfer time (in seconds); SR: Standing Ratio (in \%); S: Speed; WSLR: Weight symmetry between right and left lower limbs.

\section{Discussion}

Complaints related to musculoskeletal disabilities during pregnancy are increasingly discussed with regard to the care provided during the pregnancypuerperal cycle. In this context, lumbopelvic pain (LPP) represents a major problem often faced by many pregnant women [13]. Previous studies report that pain complaints may be of sufficient intensity and duration to affect the quality of life of the pregnant woman, able to interfere in performing daily activities such as sit-to-stand and walking, in addition to compromising their performance at work [13-15].
The main finding of our study showed that there is no difference in the dynamic postural balance variables (during sit-to-stand activity) when considering the presence or absence of LPP $(p>0.07)$. These findings contradict the results of Öztürk et al. (2016), who evaluated the effects of LPP on postural balance and the risk of falls in women during the third trimester, identifying their negative influence on the postural balance of the participants [21]. However, it is necessary to take into account the clinical importance of this result. This is a common movement of daily activities and one that pregnant women report difficulty in performing. Therefore, it is important that physical therapists are aware 
of this complaint in pregnant woman in order to adopt adequate evaluation and conduct in order to minimize or overcome inconveniences established during this period, facilitating the accomplishment of functional activities.

The analysis of postural balance variables based on gestational trimesters while considering the presence/absence of LPP shows a statistically significant difference for the VFEC (Velocity of oscillation on a Firm surface and Eyes Closed) on the $m$ CTSIB test (static balance) among pregnant women during the third trimester $(p=0.001)$. This finding corroborates previous studies [21, 22] in which a longitudinal study to evaluate the displacement of the pressure center (PC) was conducted using stabilometry with 20 women during the three gestational trimesters, revealing that pregnant women with their eyes closed and feet together present a greater displacement of the PC than when their eyes were open and feet apart [23]. In evaluating the influence of visual information on the balance of 12 pregnant women through absence of visual afferences, observed that the oscillation velocity was higher among the pregnant women during the second and third trimesters than in nonpregnant women [22].

In this context, it is known that the maintenance of postural balance is attributed to the postural control system, which refers to the functions of the sensory, visual and vestibular systems mediated by the central nervous system (CNS) [11]. A previous study has shown that the visual system is the most requested system for maintaining postural balance, especially among young adults. In this circumstance, the absence of visual afferences is capable of negatively influencing the individual's performance in maintaining their postural balance [11], which would justify the findings of our study during the evaluation of the VFEC variable (Velocity of oscillation on a Firm surface and Eyes Closed).

It is also known that the lower the CG, the higher the degree of postural stability is and the larger the support base, when the CG projection remains within the support base and the higher the body weight. However, previous studies have shown that the higher rate of weight gain during the third gestational trimester would justify the reduction of postural balance during this phase $[3,22,24]$. This factor can be explained by the non-homogeneous distribution of the body weight, in addition to the asymmetrical laxity of the joints, promoting greater postural instability in pregnant women mainly due to hormonal action during the gestational period.

It should also be considered that the pelvis balance depends on the postural condition and coordination, support and strength of the muscles that constitute the abdomino-lumbo-pelvic enclosure. Thus, the most current hypothesis about the genesis of LPP is based on the concept of lumbopelvic stabilization, which allows proper maintenance of the bone, muscle and ligament system by the pre-programmed activation of the musculature that constitutes the stabilization system. Among these muscles are the transverse abdomen [25], diaphragm, the multifidus muscles and the pelvic floor. This activation occurs regardless of movement direction and acts as a protective factor for spine stability.

The stability of the spine depends on the integration between 3 mechanisms: 1 ) the anatomical configuration or passive system consisting of the vertebral bodies, facet joints, joint capsules, spinal ligaments and intervertebral discs; 2) closure force or active system, consisting of muscles, fascias and tendons; and 3) the neural system or neural function, which receives information from the passive and active systems through the receptors, and has the role of capturing balance changes, as well as determining specific adjustments, and is therefore related to motor control (muscular activation) [25].

Thus, if any of the stabilization system mechanisms are unable to provide adequate support to overcome the biomechanical overload due to gestation, there may be damage in the load transfer to the pelvis, resulting in the appearance of painful symptomatology [25]. It is known that an increase in the size of the gravid uterus leads to an inefficient or insufficient support of the abdominal muscles [26], which are in an unfavorable lengthtension relationship. This fact makes this muscle temporarily lose its ability to maintain the spine's stability. Associated with this phenomenon, changes in the bony structure of the pelvis elevate the tension level of the paravertebral lumbar muscles [27], with consequent overload in the inferior region of the spine/lower back.

In this context, Takeda et al. [8] report that the occurrence of posterior displacement in the CG during the sit-to-stand movement would justify the difficulty of the pregnant woman in controlling her body against gravity during the movement. 
Therefore, this fact would require an anterior flexion of the trunk accompanied by an ankle dorsiflexion in order to control the sitting movement [8]. Gilleard et al. [28] reported that the upper trunk and head segments have their displacement parameters and velocities altered during the movement of getting up from a chair, suggesting different movement strategies for each body segment as pregnancy progresses. Thus, it can be assumed that different movement strategies are necessary for the individual to accomplish the task of sitting and getting up, depending on their ability to maintain control of their postural balance $[26,27,29]$.

Thus, pregnant women would undergo adaptations in order to minimize the effects of the limitation imposed by the biomechanical adaptations, increasing their postural stability during the movement [30]. The responses developed by pregnant women are believed to be more sensitive to the processing and integration of the visual, proprioceptive, vestibular and somatosensory systems than the changes imposed by gestation [31]. In addition, it is suggested that the difficulty in performing a seated task during gestation may also result from the limitations related to the environment in which the pregnant woman is inserted rather than being a unique effect of the adaptations due to pregnancy [28], which would justify the results found in our study.

Among the aspects considered risk factors for the development of gestational low back pain, we can mention: age, number of previous pregnancies, education level, low economic status, gestational age, fetal weight, maternal BMI and previous history of lumbar pain [12]. Our sample consisted of women with a good level of education who reported LPP of mild to moderate intensity, which may further justify the results found in this article. This is because patients with chronic lumbar pain and lower educational levels appear to have less knowledge about self-care; while those with greater social support may have access to better personal care, thus reducing their perceived pain and its consequent interference with daily activities [13].

Our findings also point to the frequency of disability generated by pain on daily activities obtained by the Owestry Disability Index (ODI). All participants with LPP complaints reported some level of disability (minimal, moderate or severe) detected by this instrument. The majority of pregnant women reported minimal and moderate disability, as observed in the studies by Madeira et al. (2013) and Sousa et al. [12, 15]. Although the participants in this study did not report complete inability to perform daily activities to the detriment of the LPP complaint, some level of partial and temporary limitations were found in pregnant women. Thus, the results of this study are extremely important for developing a therapeutic plan aimed at the gestational period with the objective of prevention and treatment of this musculoskeletal dysfunction.

\section{Conclusion}

When considering the prevalence of LPP in the population of pregnant women, some authors suggest that the frequency of pain complaints increases throughout pregnancy, especially during the third gestational trimester, when muscle and ligament overload is greater due to the hormonal action and the growth of the gravid uterus [12, 21]. These findings corroborate the results of this study, which identified a higher prevalence of LPP in women during the third trimester.

Thus, it is known that maintaining postural balance is a complex task, and pregnant women resort to compensatory postural adjustments to perform the most diverse daily activities due to the intense transformations resulting from pregnancy.

Literature findings show that the activity of getting up from a chair becomes more difficult as pregnancy progresses and is influenced by lumbopelvic pain (LPP). However, no statistically significant differences were found regarding the effect of LPP on maintaining postural balance during sit-to-stand activities in pregnant women in this study.

Studies that analyze the impact of LPP on the dynamic balance of pregnant women are still scarce. Thus, we observed a need for more research on the subject considering this specific population. Our sample consisted of nulliparous women with single fetus pregnancies, a high level of education, and no LPP before pregnancy; factors that may have restricted the findings of this study. We also suggest that future studies evaluate the association of LPP on postural balance variables, incorporating a larger sample number and objective assessment instruments for pain complaints. 


\section{Acknowledgments}

To the Brazilian Agency Conselho Nacional de Desenvolvimento Científico e Tecnológico (CNPq) for their assistant and support, as well as to the pregnant women who agreed to participate in this study.

\section{References}

1. Aguiar L, Santos-Rocha R, Vieira F, Branco M, Andrade C, Veloso A. Comparison between overweight due to pregnancy and due to added weight to simulate body mass distribution in pregnancy. Gait Posture. 2015;42(4):511-7.

2. Ribeiro SO, Sousa VPS, Viana ESR. Influence of virtual reality on postural balance and quality of life of pregnant women : controlled clinical trial randomized. Fisioter Mov. 2017;30(Suppl 1):111-20.

3. Inanir A, Cakmak B, Hisim Y, Demirturk F. Evaluation of postural equilibrium and fall risk during pregnancy. Gait Posture. 2014;39(4):1122-5.

4. Gottschall JS, Sheehan RC, Downs DS. Pregnant women exaggerate cautious gait patterns during the transition between level and hill surfaces. J Electromyogr Kinesiol. 2013;23(5):1237-42.

5. Ersal T, McCrory JL, Sienko KH. Theoretical and experimental indicators of falls during pregnancy as assessed by postural perturbations. Gait Posture. 2014;39(1):218-23.

6. Sunaga Y, Anan M, Shinkoda K. Biomechanics of rising from a chair and walking in pregnant women. Appl Ergon. 2013;44(5):792-8.

7. Bhardwaj A, Nagandla K. Musculoskeletal symptoms and orthopaedic complications in pregnancy: pathophysiology, diagnostic approaches and modern management. Postgrad Med J. 2014;450-60.

8. Takeda K. A kinesiological analysis of the standto-sit during the third trimester. J Phys Ther Sci. 2012;24(7):621-4.
9. Ribeiro SO, Sousa VPS, Viana ESR. Influence of a virtual reality-based exercise protocol on the sitto-stand activity kinematic variables in pregnant women: a randomized controlled trial. Motriz. 2017;23(3):1-8.

10. Mazzà C, Benvenuti ÃF, Bimbi C, Stanhope SJ. Association between subject functional status, seat height, and movement strategy in sit-to-stand performance. J Am Geriatr Soc. 2004;52:1750-4.

11. Duarte M, Freitas SMSF. Revisão sobre posturografia baseada em plataforma de força para avaliação do equilíbrio. Rev Bras Fisioter. 2010;14(3):183-92.

12. Gaerlan MG, Alpert PT, Cross C, Louis M, Kowalski S. Postural balance in young adults: the role of visual, vestibular and somatosensory systems. J Am Acad Nurse Pract. 2012;14(6):375-81.

13. Madeira HGR, Garcia JBS, Lima MVV, Serra HO. Incapacidade e fatores associados à lombalgia durante a gravidez. Rev Bras Ginecol Obstet. 2013;35(12):541-8.

14. Yan CF, Hung YC, Gau ML, Lin KC. Effects of a stability ball exercise programme on low back pain and daily life interference during pregnancy. Midwifery. 2014;30(4):412-9.

15. Glinkowski WM, Tomasik P, Walesiak K, Głuszak M, Krawczak K, Michoński J, et al. Posture and low back pain during pregnancy - 3D study. Ginekol Pol. 2016;87(8):575-80.

16. Sousa VPS, Ribeiro SO, Aquino CMR, Viana ESR. Análise da relação entre dor lombar, idade gestacional e qualidade de vida durante a gravidez. Ter Man. 2011;9(46):769-73.

17. Martins RF, Silva JLP. Prevalência de dores nas costas na gestação. Rev Assoc Med Bras. 2005;51(3):144-7.

18. Vigatto R, Alexandre NM, Correa HRF. Development of a Brazilian Portuguese version of the Oswestry Disability Index: cross-cultural adaptation, reliability, and validity. Spine (Phila Pa 1976). 2007;32:481-6. 
19. Sousa VPS, Ribeiro SO, Aquino CMR, Viana ESR. Quality of sleep in pregnant woman with low back pain. Fisioter Mov. 2015;28(2):319-26.

20. Natus Newborn Care. NeuroCom Balance Master Systems. Preasanton: Natus; 2016. Available from: http://bit.ly/2HrSwmi.

21. Özturk G, Geler KD, Aydog E, Kaspar Ç, Ugurel B. Effects of lower back pain on postural equilibrium and fall risk during the third trimester of pregnancy. J Matern Fetal Neonatal Med. 2016;29(8):358-62.

22. Butler EE, Colón I, Druzin ML, Rose J. Postural equilibrium during pregnancy: decreased stability with an increased reliance on visual cues. Am J Obstet Gynecol. 2006;195(4):1104-8.

23. Oliveira LF, Vieira TM, Macedo AR, Simpson DM, Nadal J. Postural sway changes during pregnancy: a descriptive study using stabilometry. Eur J Obstet Gynecol Reprod Biol. 2009;147(1):25-8.

24. Moccellin A, Driusso P. Adjustments in static and dynamic postural control during pregnancy and their relationship with quality of life: a descriptive study. Fisioterapia. 2012;34(5):196-202.

25. Gouveia KMC, Gouveia EC. O músculo transverso abdominal e sua função de estabilização da coluna lombar. Fisioter Mov. 2008;21(3):45-50.
26. Borg-Stein J, Dugan SA. Musculoskeletal disorders of pregnancy, delivery and postpartum. Phys Med Rehabil Clin N Am. 2007;18(3):459-76.

27. Sabino J, Grauer JN. Pregnancy and low back pain. Curr Rev Musculoskelet Med. 2008;1(2):137-41.

28. Gilleard WL, Crosbie J, Smith R. Static trunk posture in sitting and standing during pregnancy and early postpartum. Arch Phys Med Rehabil. 2002;83(12):1739-44.

29. Fujimoto M, Chou LS. Dynamic balance control during sit-to-stand movement: an examination with the center of mass acceleration. J Biomech. 2012;45(3):543-8.

30. Gilleard W, Crosbie J, Smith R. A longitudinal study of the effect of pregnancy on rising to stand from a chair. J Biomech. 2008;41:779-87.

31. McCrory JL, Chambers AJ, Daftary A, Redfern MS. Dynamic postural stability in pregnant fallers and non-fallers. BJOG. 2010;117(8):954-62.

Received in 04/12/2018

Recebido em 12/04/2018

Recibido en $12 / 04 / 2018$

Approved in 03/07/2019

Aprovado em 07/03/2019

Aprobado en 07/03/2019 